\title{
Mounier-Kuhn syndrome: more than just a cough
}

\author{
Christine Azzopardi, ${ }^{1}$ Joseph Attard, ${ }^{2}$ Edith Vassallo, ${ }^{1}$ Reuben Grech ${ }^{1}$
}

${ }^{1}$ Department of Medical Imaging, Mater Dei Hospital, Msida, Malta

${ }^{2}$ Mater Dei Hospital, Msida, Malta

\section{Correspondence to}

Dr Christine Azzopardi, chrissyazz@yahoo.com

Accepted 26 August 2014

\section{DESCRIPTION}

A 35-year-old man presented with a chronic productive cough and a history of recurrent lower respiratory tract infections. Physical examination was unremarkable as were routine blood investigations.

A chest radiograph demonstrated dilation of the trachea and main bronchi. Multiple perihilar cysts with air-fluid levels were seen (figure 1). Contrast-enhanced chest CT confirmed tracheal dilation with multiple tracheal diverticulae present in the posterior aspect of the proximal trachea (figure 2). Both main bronchi were also dilated. Bilateral, cystic spaces with air-fluid levels, in keeping with cystic bronchiectasis were seen to involve both lower lung zones, sparing the lung apices. This can be appreciated on coronal reformats (figure 3). Tracheal dilation and diverticulae were observed on bronchoscopy, confirming the diagnosis of tracheobronchomegaly.

Mounier-Kuhn syndrome, also described as tracheobronchomegaly, is a rare condition marked by tracheal and bronchial dilatation. Presentation is usually that of recurrent lower respiratory tract infections. ${ }^{1}$ The diagnosis is performed radiologically and is confirmed by bronchoscopy and lung function tests. These demonstrate an obstructive picture with a reduced forced expiratory volume in $1 \mathrm{~s}\left(\mathrm{FEV}_{1}\right)$ and forced vital capacity (FVC) resulting in a $\mathrm{FEV}_{1} / \mathrm{FVC}$ of less than $70 \%$. A tracheal diameter more than $3 \mathrm{~cm}$, usually measured $2 \mathrm{~cm}$ above the aortic arch is diagnostic. $^{2}$ A hereditary link is suggested by the occurrence of this condition in Ehlers-Danlos and cutis laxa. ${ }^{3}$ The consequence of this disease is impaired clearance of mucous resulting in recurrent

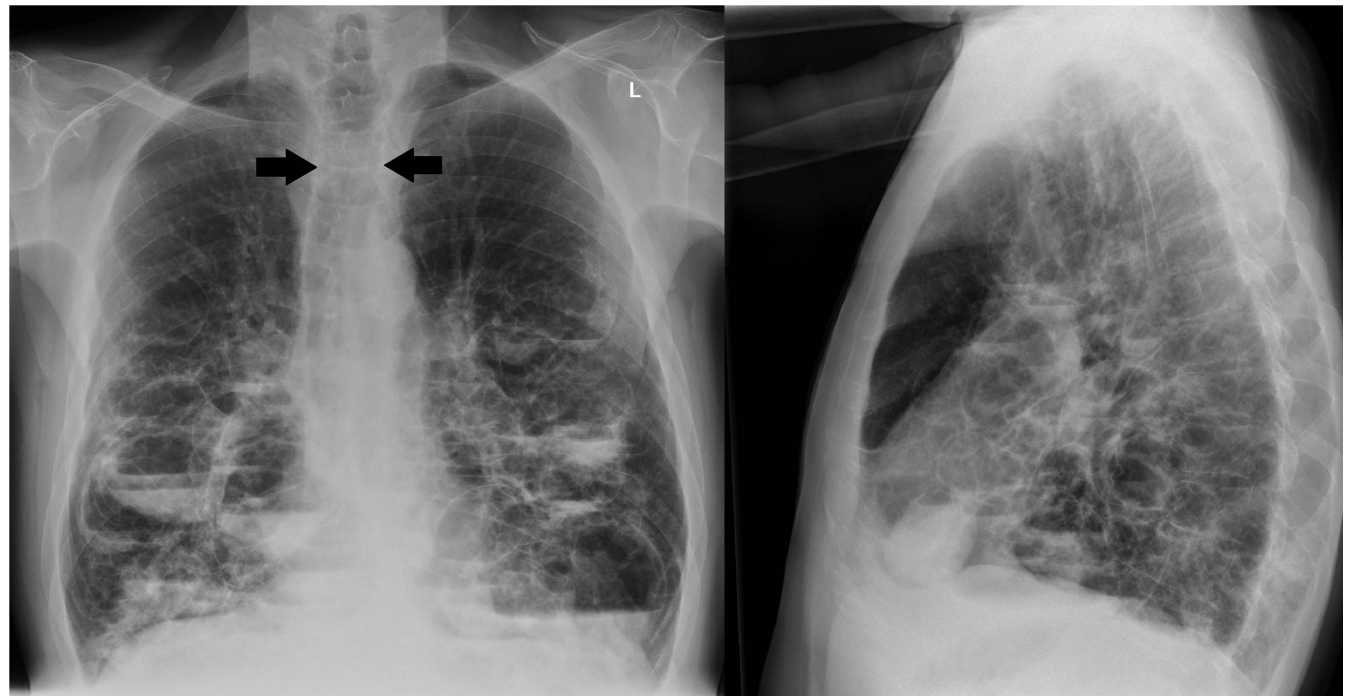

Figure 1 Posterior-anterior (left) and lateral (right) chest X-ray demonstrating a dilated trachea (arrows) and perihilar cystic bronchiectasis with air-fluid levels.

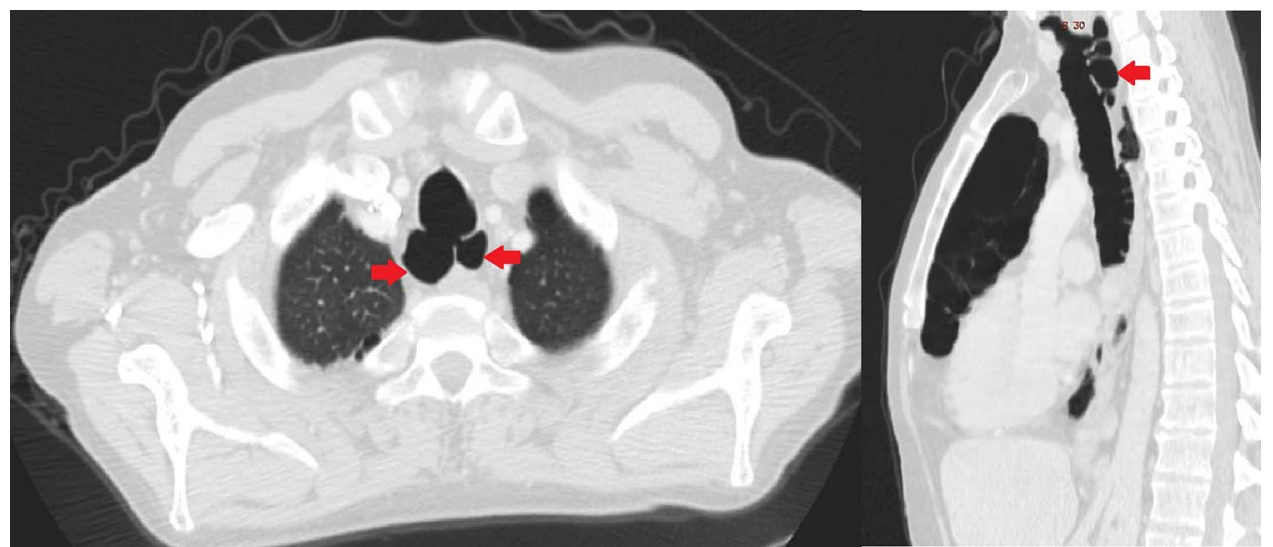

To cite: Azzopardi $C_{\text {, }}$ Attard J, Vassallo $E_{\text {, et al. }}$ BMJ Case Rep Published online: [please include Day Month Year] doi:10.1136/ bcr-2014-206155 


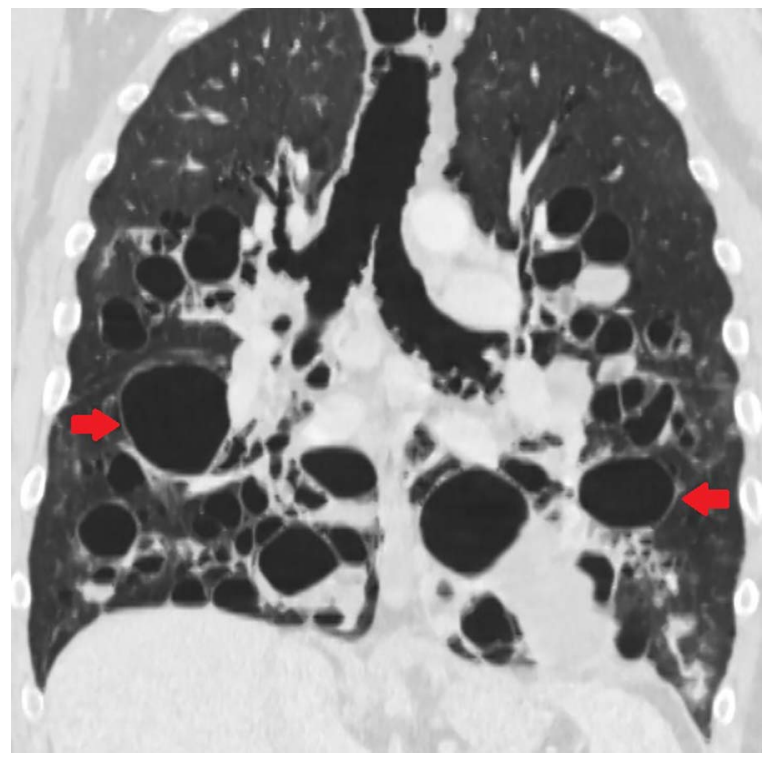

Figure 3 Coronal reformat demonstrating dilated trachea and main bronchi together with cystic bronchiectasis (arrows).

pneumonias, emphysaema, bronchiectasis and parenchymal scarring. ${ }^{3}$ Chest physiotherapy and long-term antibiotics are the mainstay of treatment.

\section{Learning points}

- Should be considered in the differential diagnosis of a chronic cough.

- CT of the chest is diagnostic as it clearly demonstrates tracheal and bronchial dilatation.

- Physiotherapy and antibiotics are the mainstay of treatment.

Contributors CA and JA performed the literature review and drafted the write up of the article. EV and RG made the radiological diagnosis of the case and reported the imaging findings.

Competing interests None.

Patient consent Obtained.

Provenance and peer review Not commissioned; externally peer reviewed.

\section{REFERENCES}

1 Celik B. Mounier-Kuhn syndrome: a rare cause of bronchial dilation. Tex Heart Inst J 2011;38:194-6.

2 Shin MS. Tracheobronchomegaly (Mounier-Kuhn syndrome): CT diagnosis. AJR Am J Roentgenol 1988;150:777-9.

3 Schwartz M. Tracheobronchomegaly. Chest 1994;106:1589-90.

Copyright 2014 BMJ Publishing Group. All rights reserved. For permission to reuse any of this content visit

http://group.bmj.com/group/rights-licensing/permissions.

BMJ Case Report Fellows may re-use this article for personal use and teaching without any further permission.

Become a Fellow of BMJ Case Reports today and you can:

- Submit as many cases as you like

- Enjoy fast sympathetic peer review and rapid publication of accepted articles

- Access all the published articles

- Re-use any of the published material for personal use and teaching without further permission

For information on Institutional Fellowships contact consortiasales@bmjgroup.com

Visit casereports.bmj.com for more articles like this and to become a Fellow 